\title{
2018 Update of the EULAR recommendations for the management of large vessel vasculitis
}

\author{
Bernhard Hellmich (1) , ${ }^{1}$ Ana Agueda, ${ }^{2}$ Sara Monti, ${ }^{3}$ Frank Buttgereit, ${ }^{4}$ \\ Hubert de Boysson, ${ }^{5}$ Elisabeth Brouwer, ${ }^{6}$ Rebecca Cassie, ${ }^{7}$ Maria C Cid, ${ }^{8}$ \\ Bhaskar Dasgupta, ${ }^{9}$ Christian Dejaco (D) , ${ }^{10,11}$ Gulen Hatemi (D) , ${ }^{12}$ Nicole Hollinger, ${ }^{13}$ \\ Alfred Mahr, ${ }^{14}$ Susan P Mollan, ${ }^{15,16}$ Chetan Mukhtyar (D) , ${ }^{17}$ Cristina Ponte, $^{18,19}$ \\ Carlo Salvarani, ${ }^{20}$ Rajappa Sivakumar, ${ }^{21}$ Xinping Tian, ${ }^{22}$ Gunnar Tomasson, ${ }^{23}$ \\ Carl Turesson, ${ }^{24}$ Wolfgang Schmidt, ${ }^{25}$ Peter M Villiger, ${ }^{26}$ Richard Watts, $^{27}{ }^{2}$ Chris Young, ${ }^{28}$ \\ Raashid Ahmed Luqmani ${ }^{29}$
}

\begin{abstract}
Handling editor Josef $\mathrm{S}$ Smolen

- Additional material is published online only. To view please visit the journal online (http://dx.doi.org/10. 1136annrheumdis-2019215672).
\end{abstract}

For numbered affiliations see end of article.

\section{Correspondence to}

Prof Dr Bernhard Hellmich, Klinik für Innere Medizin, Rheumatolgie und Immunologie, Medius Kliniken, Eberhard Karls Universität Tübingen, 73230

Kirchheim-Teck, Germany; b.hellmich@medius-kliniken.de

Received 6 May 2019 Revised 10 June 2019 Accepted 10 June 2019 Published Online First 3 July 2019

\section{Check for updates}

(C) Author(s) (or their employer(s)) 2020. No commercial re-use. See rights and permissions. Published by BMJ.

To cite: Hellmich $B$, Agueda A, Monti S, et al. Ann Rheum Dis 2020;79:19-30.

\section{ABSTRACT}

Background Since the publication of the European League Against Rheumatism (EULAR) recommendations for the management of large vessel vasculitis (LVV) in 2009, several relevant randomised clinical trials and cohort analyses have been published, which have the potential to change clinical care and therefore supporting the need to update the original recommendations.

Methods Using EULAR standardised operating procedures for EULAR-endorsed recommendations, the EULAR task force undertook a systematic literature review and sought opinion from 20 experts from 13 countries. We modified existing recommendations and created new recommendations.

Results Three overarching principles and 10 recommendations were formulated. We recommend that a suspected diagnosis of LVV should be confirmed by imaging or histology. High dose glucocorticoid therapy (40-60 mg/day prednisone-equivalent) should be initiated immediately for induction of remission in active giant cell arteritis (GCA) or Takayasu arteritis (TAK). We recommend adjunctive therapy in selected patients with GCA (refractory or relapsing disease, presence of an increased risk for glucocorticoid-related adverse events or complications) using tocilizumab. Methotrexate may be used as an alternative. Non-biological glucocorticoidsparing agents should be given in combination with glucocorticoids in all patients with TAK and biological agents may be used in refractory or relapsing patients. We no longer recommend the routine use of antiplatelet or anticoagulant therapy for treatment of LVV unless it is indicated for other reasons.

Conclusions We have updated the recommendations for the management of LVV to facilitate the translation of current scientific evidence and expert opinion into better management and improved outcome of patients in clinical practice.

\section{BACKGROUND}

Rapid diagnosis and effective treatment are required in large vessel vasculitis (LVV) in order to treat symptoms, but more importantly, to reduce the risk of complications such as blindness in giant cell arteritis (GCA) and aortic aneurysm or vascular stenosis in GCA and Takayasu arteritis (TAK). In April 2008, the first recommendations of the
European League against Rheumatism (EULAR) for managing LVV were published. ${ }^{1}$ These recommendations have provided guidance to clinicians and researchers and have been widely cited. Since then, the results of several randomised clinical trials and cohort analyses have become available and the EULAR recommendations on imaging in LVV have been published recently. ${ }^{2}$

In light of these and other fundamental developments affecting key areas of management, the goal of the current project was to re-evaluate the literature in order to update the EULAR recommendations for the management of LVV.

\section{METHODS}

The recommendations were drafted according to the 2014 update of the EULAR standardised operating procedures (SOPs) for the development of EULARendorsed recommendations and the updated version of the Appraisal of Guidelines for Research \& Evaluation (AGREE II) recommendations, where applicable (see online supplementary file 1 for a full description of methods). ${ }^{34}$ The task force consisted of 20 clinical experts (including rheumatologists, internists, immunologists, a neurologist, a neuro-ophthalmologist and an epidemiologist), from 11 European countries, India and China, two fellows (AA, SM), one health professional and two patients affected by the diseases under study.

Based on results of a Delphi survey among the task force, we defined eight key research questions addressing the management and treatment of LVV. As the original systematic literature review (SLR) for the 2008 recommendations dated back 10 years ago with different methodology, it was decided to conduct two completely new SLRs without time limits, focusing on general management and treatment, respectively (table 1).

The following databases were used: MEDLINE, EMBASE and Cochrane CENTRAL. Each article was assigned a level of evidence (LoE) according to the standards of the Oxford Centre for EvidenceBased Medicine and was systematically assessed for bias. ${ }^{3}$ The methods and results of the two SLRs are published separately. ${ }^{56}$

During a face-to-face meeting, task force members independently voted on each recommendation. 


\begin{tabular}{|c|c|}
\hline SLR 1: General Management & SLR 2: Treatment \\
\hline $\begin{array}{l}\text { Diagnosis: recognition, referral criteria, fast-track diagnosis, role of imaging for diagnosis, } \\
\text { role of biopsy for diagnosis, interdisciplinary work-up, considerations for sub-types of } \\
\text { disease such as cranial/ischaemic/large vessel, isolated aortitis, IgG4-related disease, LVV } \\
\text { disease in other vasculitides. } \\
\text { Prognostic and therapeutic implications of disease phenotypes: cranial vs extra-cranial, } \\
\text { isolated aortitis, other forms including lgG-4 related disease, imaging, other biomarkers, } \\
\text { comorbidities and complications, disease damage versus activity. } \\
\text { Long-term follow-up of patients: clinical assessments and frequency, imaging, patient- } \\
\text { reported outcomes, physical therapies and management of complications. } \\
\text { Patient education and other aspects of patients-centred care. }\end{array}$ & $\begin{array}{l}\text { Drug therapy: dosing, length of therapy, outcome and treatment-related } \\
\text { side effects for the following drugs: glucocorticoids, methotrexate and other } \\
\text { non-biological immunosuppressive agents, tocilizumab and other biological } \\
\text { agents. } \\
\text { Specific treatment of organ complications: loss of vision and stroke), } \\
\text { relapsing, refractory, glucocorticoid-dependent disease. } \\
\text { Revascularisation procedures: indications for referral, management of } \\
\text { aneurysms and/or vessel stenosis. } \\
\text { Adjunctive therapies and prophylaxis: aspirin, cardiovascular and } \\
\text { cerebrovascular disease, infections, vaccination, osteoporosis. }\end{array}$ \\
\hline
\end{tabular}

LVV, large vessel vasculitis; SLR, systematic literature review.

Agreement on each recommendation and on the overarching principles on a scale of $0-10$ (10 meaning full agreement) was given anonymously after the meeting by e-mail. A research agenda was formulated based on controversial issues and gaps in the evidence. The final manuscript was approved by the EULAR Executive Committee.

\section{RESULTS}

\section{General aspects}

The objective of the updated recommendations is to give advice on the management of LVV to rheumatologists and other health professions involved in the care of these patients. Because EULAR recommendations on imaging in LVV have been published recently, ${ }^{2}$ the task force agreed to refer to these recommendations removing topics regarding imaging from the update of the management recommendations.

To reduce confusion currently existing in the literature we propose new consensus definitions for disease activity states in LVV (table 2), based on the concept of activity states developed for the EULAR recommendations for small vessel vasculitides (SVV). ${ }^{7}$

The new definitions are consensus based and do not derive from the SLR. They differ in some details from definitions used in recent clinical trials (for comparison see online supplementary file 2). By analogy to the EULAR definitions for $\mathrm{SVV}^{7}$, we suggest using the term 'relapse' consistently, but avoiding the term 'flare'. We propose a distinction between major and minor relapses because the prognosis and treatment of relapses in LVV depends on the presence of ischaemia and/or development or progression of vascular damage. In contrast to SVV, true refractory disease in LVV is very rare because patients usually respond well to high dose glucocorticoids (GCs). However, in the past, the term 'refractory' was sometimes used for patients with LVV and GC-dependent disease that relapsed when GCs were tapered. We propose that the activity state 'refractory' should be used to reflect the difficulty in achieving disease control despite the patient remaining on an appropriate treatment schedule (which would include tapering of the GC dose). primary or secondary to infection (eg, syphilis) or other systemic diseases were recognised as separate entities by the Chapel Hill consensus conference. ${ }^{8}$ The SLR revealed only very low evidence on management of these rare entities, which did not allow us to generate separate recommendations. Therefore, we encourage further research on these subtypes, as outlined in the research agenda below.

\section{Overarching principles}

The task force identified general principles that were deemed fundamental for the management of patients with LVV (table 3).
In 2012, IgG4-related (peri-)aortitis and isolated aortitis, either

These principles were consensus based and did not directly result from the SLR. The overarching principles and the specific recommendations are listed in table 3.

\section{Recommendations}

All patients presenting with signs and symptoms suggestive of GCA should be urgently referred to a specialist team for further multidisciplinary diagnostic work-up and management

Untreated active GCA is an emergency and carries a substantial risk of permanent visual loss and other ischaemic complications. Therefore, we recommend that all patients $\geq 50$ years of age presenting with acute or subacute onset of signs and

Table 2 EULAR consensus definitions for disease activity states in GCA and other types of LVV

\begin{tabular}{|c|c|}
\hline Activity state & EULAR consensus definition \\
\hline Active disease & $\begin{array}{l}\text { 1. The presence of typical signs or symptoms of active LVV } \\
\text { (table 4). } \\
\text { 2. At least one of the following: } \\
\text { a. Current activity on imaging or biopsy. } \\
\text { b. Ischaemic complications attributed to LVV. } \\
\text { c. Persistently elevated inflammatory markers (after other } \\
\text { causes have been excluded). }\end{array}$ \\
\hline Flare & We do not recommend use of this term \\
\hline Relapse & $\begin{array}{l}\text { We recommend use of the terms major relapse or minor } \\
\text { relapse as defined below }\end{array}$ \\
\hline Major relapse & $\begin{array}{l}\text { Recurrence of active disease with either of the following: } \\
\text { a. Clinical features of ischaemia* (including jaw claudication, } \\
\text { visual symptoms, visual loss attributable to GCA, scalp } \\
\text { necrosis, stroke, limb claudication). } \\
\text { b. Evidence of active aortic inflammation resulting in } \\
\text { progressive aortic or large vessel dilatation, stenosis or } \\
\text { dissection. }\end{array}$ \\
\hline Minor relapse & $\begin{array}{l}\text { Recurrence of active disease, not fulfilling the criteria for a } \\
\text { major relapse }\end{array}$ \\
\hline Refractor'y & $\begin{array}{l}\text { Inability to induce remission (with evidence of reactivation of } \\
\text { disease, as defined above in 'Active disease') despite the use of } \\
\text { standard care therapy }\end{array}$ \\
\hline Remission & $\begin{array}{l}\text { Absence of all clinical signs and symptoms attributable to } \\
\text { active LVV and normalisation of ESR and CRP; in addition, for } \\
\text { patients with extracranial disease there should be no evidence } \\
\text { of progressive vessel narrowing or dilatation (frequency of } \\
\text { repeat imaging to be decided on an individual basis) }\end{array}$ \\
\hline Sustained remission & $\begin{array}{l}\text { 1. Remission for at least } 6 \text { months. } \\
\text { 2. Achievement of the individual target GC dose. }\end{array}$ \\
\hline $\begin{array}{l}\text { Glucocorticoid-free } \\
\text { remission }\end{array}$ & $\begin{array}{l}\text { Sustained remission } \\
\text { Discontinued GC therapy (but could still be receiving other } \\
\text { immunosuppressive therapy) }\end{array}$ \\
\hline
\end{tabular}




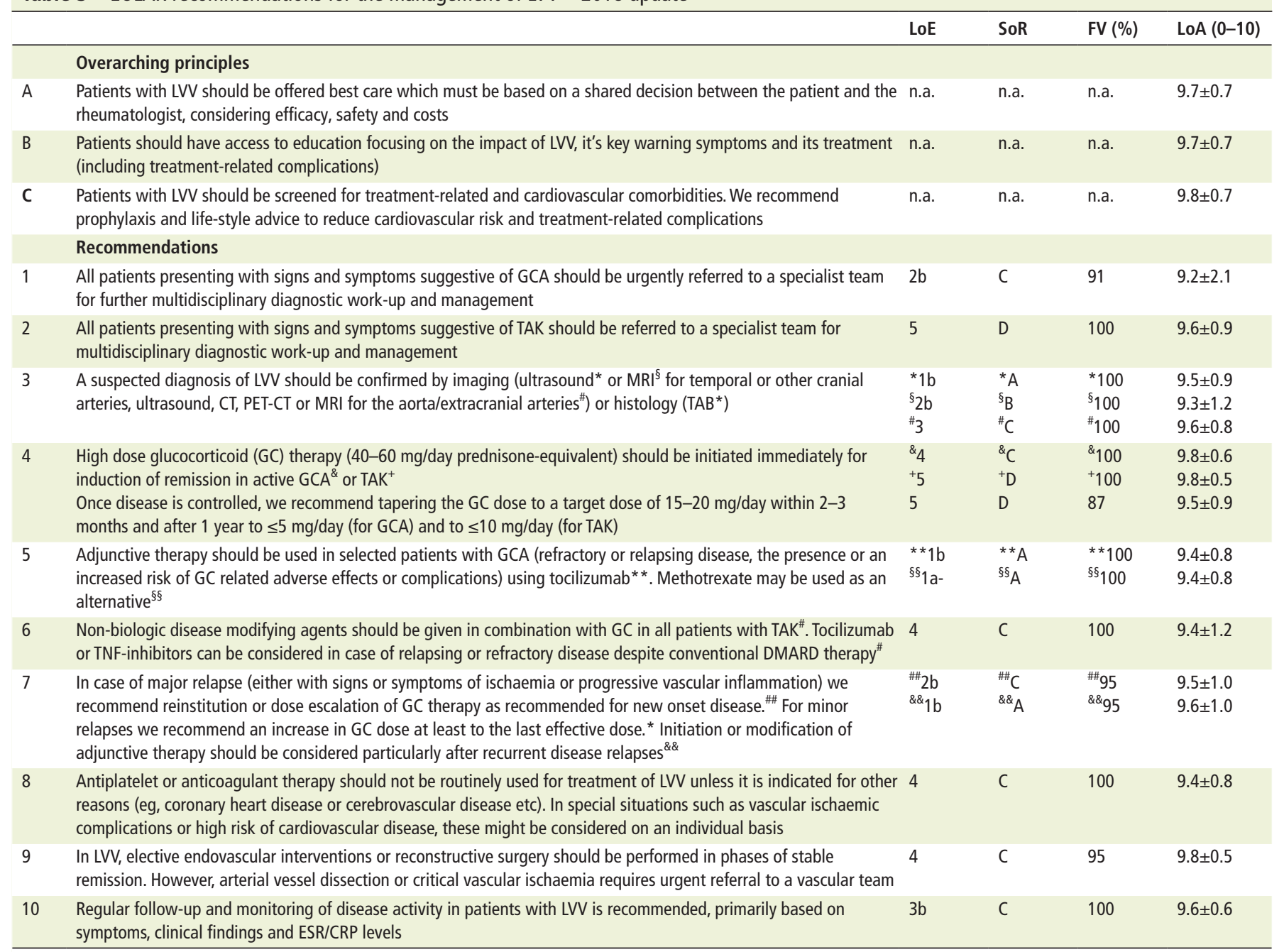

The LoE was determined for different parts of each recommendation (referred to with different signs such as * or §). The level of agreement was computed on a 0-10 scale. DMARD, disease modifying anti-rheumatic drug; FV, final vote (\% of expert panel members that agreed to the recommendation); LVV, large vessel vasculitis; LoA, level of agreement; LoE, level of evidence; NA, not applicable; SoR, strength of recommendation; TAB, temporal artery biopsy; TAK, Takayasu arteritis; TNF, tumour necrosis factor.

symptoms suggestive of GCA (table 4) and raised inflammatory markers without explanation (eg, infection) should be referred urgently to a specialist team/experienced centre for further diagnostic work-up. This team or centre should have expertise in the disease, have rapid access to up-to-date imaging ${ }^{2}$ and temporal artery biopsy (TAB) and should offer fast referral. Patients with new onset of visual symptoms should be seen as soon as possible by an ophthalmological team to exclude other causes of sudden visual disturbance. In case of signs of cerebral ischaemia, rapid review by a neurologist is recommended.

Results from two retrospective cohort studies have shown that immediate treatment of GCA patients and rapid referral to a specialised centre ('fast-track clinic') for diagnostic work-up, including imaging, within 24 hours after presenting with signs and symptoms of GCA can reduce the rate of permanent visual impairment compared with historical cohorts with routine nonurgent referral. ${ }^{9}{ }^{10}$ Although these studies were retrospective and therefore subject to bias, the available limited evidence supports rapid referral in order to confirm the diagnosis of GCA. ${ }^{11}$

Patients with both typical symptoms and increased C-reactive protein (CRP)/erythrocyte sedimentation rate (ESR) who present with acute visual disturbance should be treated before the appointment, as delaying GC therapy when visual loss is present is the strongest risk factor for permanent blindness. ${ }^{12}$ For patients without visual symptoms, there was no consensus among the task force members as to whether pre-emptive treatment with GCS should be started in all cases of suspected GCA in addition to fast referral to a specialised centre. In any case, pre-emptive therapy should only be given for a short period of time and should not delay early referral because the sensitivity of diagnostic tests decreases following treatment with GCs and to avoid unnecessary exposure to GCs of cases for whom the diagnosis of GCA is eventually not maintained. Although, the sensitivity of diagnostic tests decreases following treatment, imaging and biopsy may show features of GCA even weeks after GC therapy. ${ }^{13-16}$ Therefore, diagnostic tests to confirm a suspected diagnosis of GCA should be performed in all patients irrespective of the duration of pre-emptive therapy.

All patients presenting with signs and symptoms suggestive of TAK should be referred to a specialist team for multidisciplinary diagnostic work-up and management

The majority of symptoms of TAK (table 4) are non-specific, but should prompt a thorough examination of the arterial tree. Because there is no gold standard for the diagnosis of TAK, 


\begin{tabular}{|c|c|}
\hline Giant cell arteritis & Takayasu arteritis \\
\hline $\begin{array}{l}\text { Key symptoms } \\
\text { New-onset of persistent localised } \\
\text { headache, often in the temporal area. } \\
\text { Constitutional symptoms (eg, } \\
\text { weight loss }>2 \mathrm{~kg} \text {, low-grade fever, } \\
\text { fatigue, night sweats). } \\
\text { Jaw and/or tongue claudication. } \\
\text { Acute visual symptoms such as } \\
\text { amaurosis fugax, acute visual loss, } \\
\text { diplopia. } \\
\text { Symptoms of polymyalgia } \\
\text { reumatica. } \\
\text { Limb claudication. }\end{array}$ & $\begin{array}{l}\text { Key symptoms } \\
\text { New onset or worsening of limb } \\
\text { claudication. } \\
\text { Constitutional symptoms (eg, } \\
\text { weight loss }>2 \mathrm{~kg} \text {, low-grade fever, } \\
\text { fatigue, night sweats). } \\
\text { Myalgia, arthralgia, arthritis. } \\
\text { Severe abdominal pain. } \\
\text { Stroke, seizures (non-hypertensive), } \\
\text { syncope, dizziness. } \\
\text { Paresis of extremities. } \\
\text { Myocardial infarct, angina. } \\
\text { Acute visual symptoms such as } \\
\text { amaurosis fugax or diplopia. }\end{array}$ \\
\hline $\begin{array}{l}\text { Key findings on clinical examination } \\
\text { Tenderness and / or thickening of } \\
\text { the superficial temporal arteries with } \\
\text { or without reduced pulsation. } \\
\text { Scalp tenderness. } \\
\text { Bruits (particularly in the axilla). } \\
\text { Reduced pulses/blood pressure of } \\
\text { the upper limbs. } \\
\text { Pathological findings during } \\
\text { ophthalmologic examination } \\
\text { including anterior ischaemic optic } \\
\text { neuropathy, oculomotor cranial } \\
\text { nerve palsy/palsies, central retinal } \\
\text { artery occlusion, branch retinal artery } \\
\text { occlusion and/or choroidal ischaemia. }\end{array}$ & $\begin{array}{l}\text { Key findings on clinical examination } \\
\text { Hypertension }(>140 / 90 \mathrm{~mm} \mathrm{Hg} \text {. } \\
\text { New loss of pulses, pulse } \\
\text { inequality. } \\
\quad \text { Bruits. } \\
\quad \text { Carotidynia. }\end{array}$ \\
\hline
\end{tabular}

we recommend referral to an experienced centre for further work-up including large-vessel imaging. Studies on fast-track referral are lacking for patients with TAK. Patients with individual presentations suggesting an increased risk of ischaemic complications need a more urgent referral.

\section{A suspected diagnosis of LVV should be confirmed by imaging} (ultrasound or MRI for temporal or other cranial arteries, ultrasound, $\mathrm{CT}$, positron-emission-tomgraphy (PET)T-CT or MRI for the aorta/ extracranial arteries) or histology (TAB)

Every effort should be made to confirm a suspected diagnosis of LVV. In rare cases, both imaging and biopsy are negative. If the clinical probability in such cases is high, a provisional diagnosis of GCA may be made, which needs to be confirmed or revised during follow-up.

The original recommendations advised $\mathrm{TAB}$ in every case of suspected GCA. ${ }^{1}$ Since then, a large amount of good-quality data demonstrated that imaging and biopsy have similar diagnostic value if assessors are proficient in these techniques. ${ }^{2} 13$ The recently published EULAR recommendations for the use of imaging in LVV in clinical practice contain comprehensive advice regarding when and how the different imaging modalities should best be used in different subsets of $\mathrm{LVV}^{2}$ Several studies have shown that neither imaging nor TAB are $100 \%$ sensitive. $^{2} 1317-19$ Imaging of the temporal arteries by ultrasound or MRI identifies only $77 \%$ and $73 \%$ of cases, respectively, with clinical diagnosis as reference standard for GCA. ${ }^{142021}$ Thus, performing a second test can be considered if the first was negative but the clinical suspicion of GCA persists.

Ultrasound guidance appears not to improve the diagnostic yield of TAB. ${ }^{22}$ Biopsies should be at least $1 \mathrm{~cm}$ in length, which corresponds to a postfixation length of at least $0.7 \mathrm{~cm} .{ }^{17}$ Biopsy of the contralateral artery does not add significantly to the diagnostic yield and is therefore not routinely recommended. Overall, available data do not provide convincing evidence that any individual characteristics of the biopsy findings (eg, composition or intensity of the inflammatory infiltrate) are sufficiently predictive for subsequent clinical events to allow guidance of treatment decisions or follow-up in clinical practice. ${ }^{23-35}$

ESR and CRP are typically elevated in GCA, and it is highly infrequent $(<3 \%)$ that both are normal. ${ }^{3637}$ While several other serological biomarkers have been evaluated, none is sufficiently sensitive and specific for detection and assessment of disease activity or prediction of prognosis to recommend its use in clinical practice.

In patients with atypical clinical presentations not compatible with current disease definitions, ${ }^{8}$ an alternative diagnosis or overlapping associated diseases should be considered, in the diagnostic work up, such as for example aortitis related to IgG4-related disease, LVV in anti-neutrophil-cytoplasm (ANCA)-associated vasculitis (AAV) or other vasculitides (eg, Behçet's syndrome), or LVV secondary to spondyloarthropathies, relapsing polychondritis or infections.

High dose GC therapy (40-60 mg/day prednisone-equivalent) should be initiated immediately for induction of remission in active GCA or TAK. Once disease is controlled, we recommend tapering the $\mathrm{GC}$ dose to a target dose of 15-20 mg/day within 2-3 months and after 1 year to $\leq 5 \mathrm{mg} /$ day (for GCA) and to $\leq 10 \mathrm{mg} /$ day (for TAK)

Induction treatment with a starting GC dose of $40-60 \mathrm{mg}$ per day (all GC doses discussed in this article are prednis(ol) one equivalent) leads to remission in the majority of patients with LVV. ${ }^{38-43}$ Although the maximum genomic effect of GCs is around $100 \mathrm{mg}$ of prednisone-equivalent, ${ }^{44}$ there is no clear evidence that starting doses of above $60 \mathrm{mg}$ per day are more effective than $60 \mathrm{mg}$ per day in the prevention of ischaemic events or other relevant endpoints. It should be noted that the genomic effects of glucocorticoids depend on certain patientspecific pharmacokinetic and pharmacodynamic factors. These include for example total cell number (indirectly quantified by weight), numbers of glucocorticoid receptors per cell, and glucocorticoid receptor binding affinity. ${ }^{45} 46$ The relatively high variability of these factors explains why neither the dose-dependent efficacy of a glucocorticoid therapy can be predicted absolutely correctly, nor a weight-adapted therapy with glucocorticoids is recommended. As a consequence, and since differences between certain dosages or weight-adapted glucocorticoid dosages have not been rigourosly tested in clinical trials, the current recommendations provide dose ranges.

In patients with GCA with acute visual loss or amaurosis fugax, the administration of $0.25-1 \mathrm{~g}$ intravenous methylprednisolone for up to 3 days should be considered, because these high doses have both genomic and rapid non-genomic effects. ${ }^{445}$ However, there are only low-quality retrospective clinical data supporting this recommendation. ${ }^{47} 48$ Referral for intravenous GC therapy should not delay treatment with oral GC. The SLR revealed quality issues in both randomised controlled clinical trials (RCTs) of high dose pulse intravenous GC therapy in patients without visual symptoms. ${ }^{4041}$ In view of the limited quality of evidence, the task force recommends limiting the use of intravenous pulse GC therapy to patients with complicated GCA such as those with GCA-related visual symptoms.

We recommend tapering the GC dose, once remission has been achieved. A GC taper regimen must weigh the risk of relapse against the risk of GC-related adverse events. In GCA, relapses 
2018 EULAR RECOMMENDATIONSFOR THE MANAGEMENT OF GIANT CELL ARTERITIS

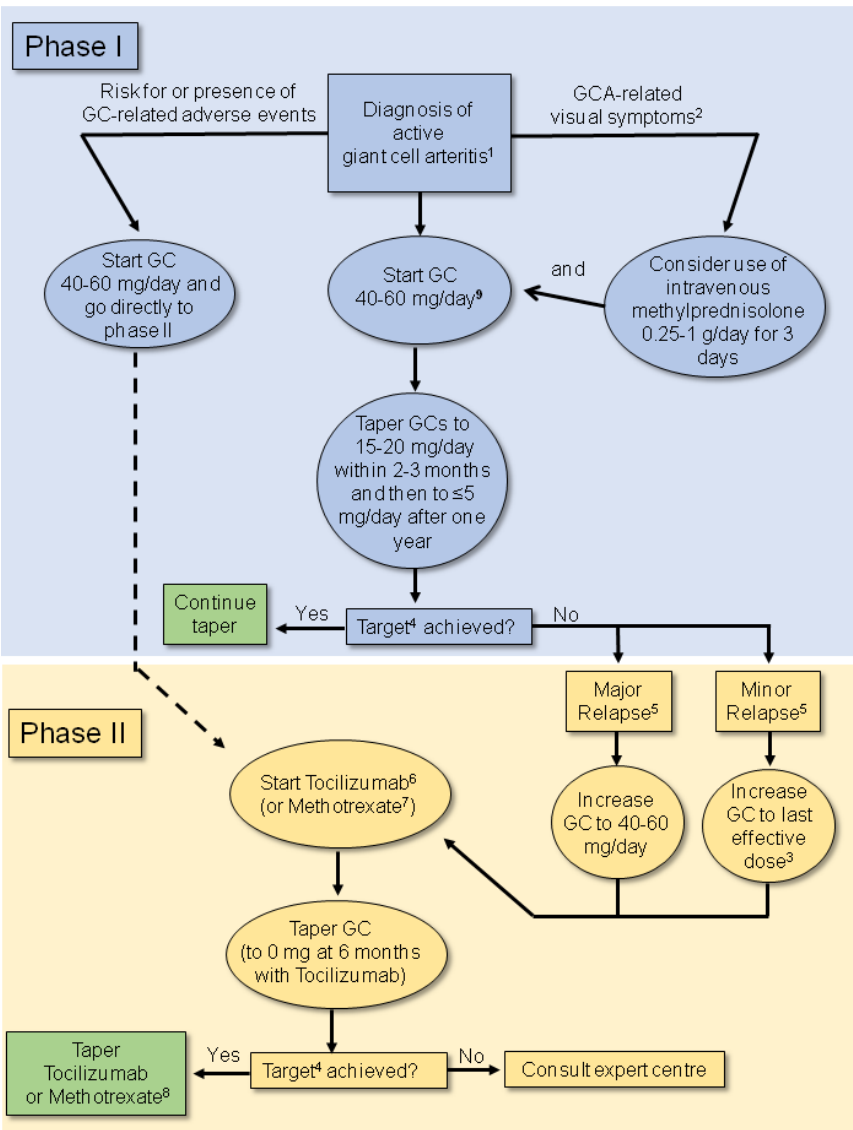

Figure 1 The 2018 EULAR algorithm for pharmacological treatment of giant cell arteritis (GCA). GC, glucocorticoids. ${ }^{1} \mathrm{~A}$ clinical diagnosis of GCA should be confirmed by either imaging or biopsy ${ }^{2}$; acute loss of vision, amaurosis fugax ${ }^{3}$;or 5-15 mg/day above the last effective dose $^{4}$; the treatment target is sustained remission (absence of clinical signs and symptoms of active GCA+normal acute phase reactants) plus ability to taper GCs to the specified target without relapse ${ }^{5}$;see table 2 for definitions ${ }^{6}$;recommended dose is $162 \mathrm{mg}^{7}$; minimum recommended dose is $15 \mathrm{mg}^{8}$; to be decided on an individual basis (lack of evidence) ${ }^{9}$ ;in patients with GCA-related visual symptoms consider a starting dose of $60 \mathrm{mg}$ prednisone per day after $\mathrm{GC}$ administration.

are common once the GC dose is tapered. Several large observational cohort studies have shown relapse rates of 34\%-75\% in patients with GCA treated with GC therapy. ${ }^{33}{ }^{49-58}$ The large variation of relapse risk in those studies was most likely due to different definitions for relapse (eg, symptoms plus CRP increase vs symptoms or CRP increase) and different tapering protocols. Each relapse requires a reinstitution or a dose-increase of GCs resulting in high cumulative GC exposure in a substantial proportion of patients which then leads to an increased risk of GC-related adverse events. ${ }^{43} 495254$ 59-64

A RCT of tocilizumab (TCZ) for treatment of GCA contained two placebo arms, one with a 26 -week GC taper protocol and the other with a 52-week taper protocol. ${ }^{38} 65$ Prednisone doses were identical in both arms until $20 \mathrm{mg} /$ day with similar numbers of relapses in both groups; from week 15 onwards the arm with the faster dose reduction appeared to be associated with a higher relapse risk. ${ }^{38}$ Data from an earlier open label prospective observational study comparing two different GC taper protocols also showed a rapid taper protocol to be less effective than a standard taper in maintaining remission. ${ }^{42}$ For patients who are not eligible for GC sparing therapy, we advise against the use of these rapid taper regimens in standard clinical practice; they reflect clinical trial designs with the intention to test the GC sparing property of experimental adjunctive agents.

In summary, considering the increased relapse risk after early taper and/or reduction of the GC dose below $5 \mathrm{mg} /$ day, we recommend tapering the GC dose in GCA to a target of 15-20 $\mathrm{mg} /$ day within 2-3 months and then to $\leq 5 \mathrm{mg} /$ day after 1 year (figure 1). Despite the lack of data regarding the optimal length of GC therapy, the majority of panel members reported that it usually takes about 2 years or more before GCs can be stopped. In patients receiving GC-sparing therapy, faster GC taper and earlier withdrawal of GCs should be considered on an individual basis, given the lack of data. In patients treated with TCZ, the published rapid 26-week GC taper may be attempted in order to significantly reduce the cumulative dose. It is not known if even faster or conversely more prolonged GC withdrawal during TCZ therapy may lead to improved outcomes.

For TAK, there are no studies comparing different GC taper protocols. Clinical experience suggests that a starting dose of 40-60 mg per day is appropriate for the majority of patients, while patients with more localised disease may respond to lower initial GC doses of 25-30 mg per day. In a recent small RCT of TCZ in TAK, a taper of GC in the placebo group by $10 \%$ per week after week four resulted in a high relapse rate (around 80\% during weeks 8-16). ${ }^{66} \mathrm{~A}$ similar relapse rate in TAK patients treated with GC monotherapy was observed in a recent RCT of abatacept. ${ }^{67}$ We therefore recommend that in patients who have reached a GC dose of $15-20 \mathrm{mg} /$ day after 2-3 months, GC doses should subsequently be reduced more slowly as compared with GCA, targeting a dose of $\leq 10 \mathrm{mg} /$ day after 1 year (figure 2).

Adjunctive therapy should be used in selected patients with GCA (refractory or relapsing disease, the presence or an increased risk of GC related adverse effects or complications) using TCZ. Methotrexate may be used as an alternative

The original recommendations suggested adjunctive immunosuppressive therapy in all patients with LVV. However, although the risk of relapse in GCA is high, a substantial number of patients with GCA treated with GC monotherapy do not relapse and are able to taper the GC dose according to a target of $\leq 5 \mathrm{mg} /$ day after 1 year ${ }^{495052}$ a dose which the EULAR task force considered to be acceptably safe. ${ }^{68}$ Therefore, we recommend limiting the use of adjunctive therapy to patients who have already developed, or have either an increased risk of developing GC-related side effects or complications, such as osteoporosis, diabetes, cardiovascular disease or glaucoma, or for relapsing patients irrespective of other risk factors. Given the high prevalence of comorbidities in the elderly population affected by GCA, the decision to use adjunctive immunosuppressive therapy in the individual patient should be balanced against potential risks for treatment-related complications, such as the increased risk of lower intestinal perforations reported in patients with rheumatoid arthritis receiving TCZ ${ }^{69}$ So far, no consistent factors have been identified at the time of diagnosis to predict an increased relapse risk and risk for subsequent high GC exposure in $\mathrm{LVV}^{49-55}$ Therefore, the identification of reliable predictive factors for relapse and prolonged GC requirement in LVV remains an important topic for future research. 
2018 EULAR RECOMMENDATIONSFOR THE MANAGEMENT OFTAKAYASU ARTERITIS

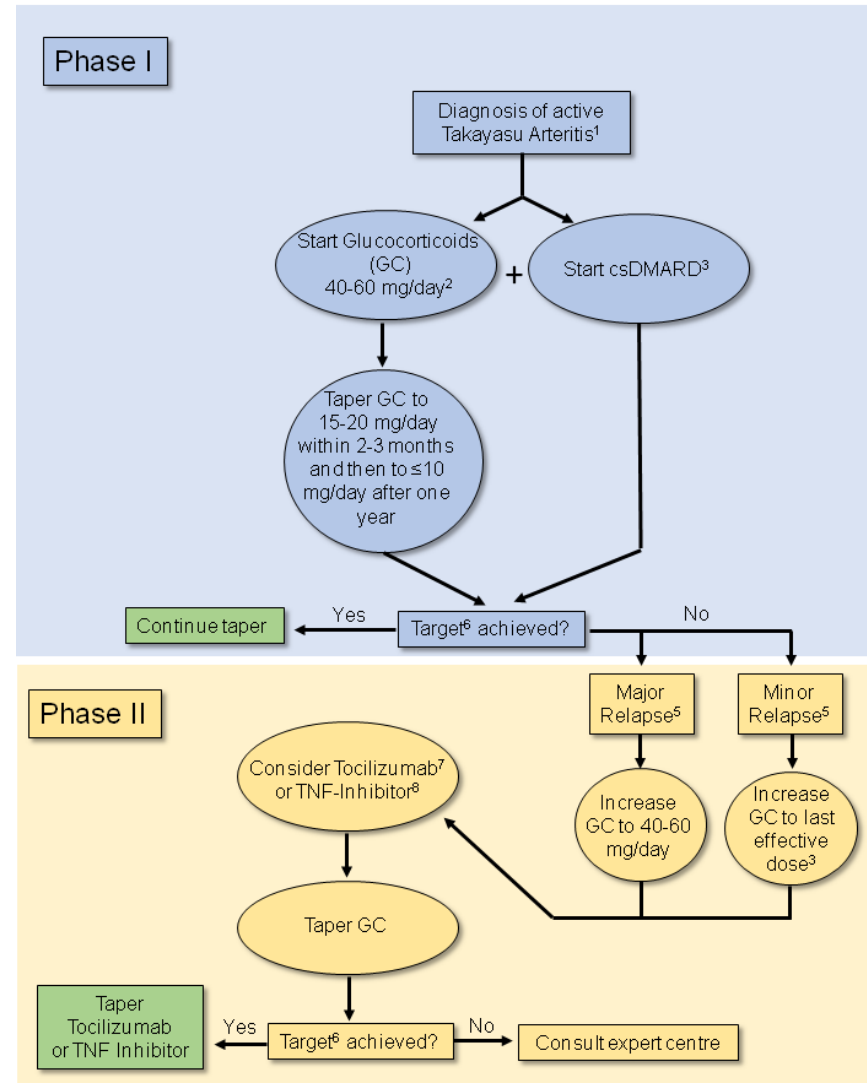

Figure 2 The 2018 EULAR algorithm for pharmacological treatment of Takayasu arteritis (TAK). csDMARD, conventional synthetic disease modifying anti-rheumatic drug; GC, glucocorticoids; TNF, tumour necrosis factor; ${ }^{1} \mathrm{~A}$ clinical diagnosis of TAK should be confirmed by imaging ${ }^{2}$; in patients with more localised disease consider lower initial dose of $25-30 \mathrm{mg} / \mathrm{day}^{3}$; methotrexate or mycophenolate mofetil, leflunomide or azathioprine (when a patient does not tolerate the first choice drug switching is an option) or cyclophosphamide (only if other treatments have failed or have not been tolerated) can be used as an alternative $^{4}$; or 5-15 mg above the last effective dose ${ }^{5}$; see table 2 for definitions ${ }^{6}$; the treatment target is sustained remission (absence of clinical signs and symptoms of active Tak associated with normal acute phase reactants) plus ability to taper GCs to the specified target without relapse ${ }^{7}$; tocilzumab is not formally licensed for use in TAK in the European Union (EU), the recommended dose is $162 \mathrm{mg}$ one time per week S.C. ${ }^{8}$; Tumor necrosis factor (TNF)-inhibitors are not formally licensed for use in TAK (when a patient does not tolerate the first choice biological switching is an option).

Two high-quality randomised controlled clinical trials in patients with GCA have shown that adjunctive administration of TCZ reduces the risk of relapse and cumulative GC exposure compared with GC monotherapy. ${ }^{3870}$ Because TCZ suppresses CRP synthesis in the liver, the presence of a normal CRP or ESR may be falsely reassuring, although sensitivity analyses in the GiACTA trial suggest that this problem did not affect the primary outcome. ${ }^{38}$ However, with the limited reliability of acute phase reactants for activity assessment in patients receiving TCZ, follow-up is largely symptom-based, which can make monitoring disease activity difficult. Thus, further studies on the role of imaging and other biomarkers for disease monitoring are needed. As high-quality long-term data are missing, it is not known if TCZ can reduce the risk of aneurysms or vascular stenosis. Hypothetically, the development of vascular long-term damage may occur despite TCZ therapy. ${ }^{71}$

Of three RCTs on the use of methotrexate (MTX) in newly diagnosed GCA, ${ }^{72-74}$ only one ${ }^{74}$ met its primary endpoint. As outlined in our SLR analysis in more detail, all of these trials were conducted more than 20 years ago, had differences in the study design and sample size which could have all accounted for the divergent outcomes. Importantly, the maximum weekly MTX doses of 7.5, 10 and $15 \mathrm{mg}$ p.o. used in all three studies were lower than those used in clinical practice today. Despite methodological limitations of the individual studies, a high quality metaanalysis using pooled individual patient data from these trials demonstrated a reduced risk of first relapse (HR 0.65, 95\% CI 0.44 to $0.98, \mathrm{p}=0.04$ ) and second relapse (HR $0.49,95 \% \mathrm{CI}$ 0.27 to $0.89, \mathrm{p}=0.02$ ), a higher probability of GC-free remission for $\geq 24$ weeks (HR 2.84, 95\% CI 1.52 to $5.28, \mathrm{p}<0.001$ ) and a lower cumulative GC dose of $-842 \mathrm{mg}$ at week 48 in patients treated with MTX versus controls. ${ }^{75}$ Of note, adverse events and early withdrawals were not different between MTX and placebo groups in the metaanalysis. ${ }^{75}$

There are no trials comparing TCZ and MTX in GCA and the differing study designs preclude strong conclusions about the potential superiority of one agent over the other. However, compared with MTX, the effect size of TCZ in terms of relapse risk reduction and GC sparing seems larger and the meta-analysis on MTX revealed hetereogeneity of results between the individual studies. Therefore, TCZ provides a higher confidence in achieving a clinically relevant treatment effect as compared with MTX. Further studies are needed to define the optimal length of treatment, GC taper regimens, cost effectiveness and monitoring. At present, there are few and only low-quality data on long-term treatment with MTX or TCZ in GCA. ${ }^{7677}$ Therefore, the duration of treatment and potential dose reductions must be decided on an individual basis. As current evidence does not suggest an excessive risk of treatment-related complications of TCZ or MTX as compared with other indications, ${ }^{38} 75$ patients should be monitored for treatment-related side effects according to existing guidelines for other diseases. ${ }^{78}$

Data for other adjunctive therapies are either sparse (abatacept), derived from low-quality studies (ustekinumab, azathioprine, leflunomide, cyclophosphamide, dapsone, etanercept) or negative (adalimumab, infliximab, cyclosporine). ${ }^{79-90}$

Non-biological disease modifying agents should be given in combination with GC in all patients with TAK. TCZ or tumour necrosis factor-inhibitors can be considered in case of relapsing or refractory disease despite conventional disease modifying antirheumatic drug therapy

In view of the high relapse rates of up to $70 \%$, the development of new vascular lesions and the inability of many patients to achieve low GC doses, ${ }^{91}{ }^{92}$ we advise that early administration of a GC-sparing agent in TAK is justified and reflects current treatment practice in more recent cohorts. ${ }^{93}{ }^{94}$ However, we acknowledge that the LoE supporting this recommendations is low.

Only two RCTs, both on biological agents, have been published, neither of which met its primary endpoint for efficacy. ${ }^{6667}$ The evidence for a use of TCZ in TAK comes largely from one small RCT showing a statistically borderline signal $(p=0.0596)$ towards reduced HR for the time to the first relapse and similar non-significant improvement in some secondary endpoints in the TCZ-treated patients. ${ }^{66}$ Additional 
experience with TCZ treatment in TAK was reported from one prospective and four retrospective case series including a total of 89 patients of which the majority had refractory or relapsing disease despite treatment with GC or other agents. ${ }^{95-100}$ Efficacy of tumour necrosis factor (TNF)-inhibitors in TAK has been reported in one prospective and several retrospective open-label uncontrolled studies/case series. ${ }^{101-111}$ Overall, the reported reductions in disease activity in all these case series need to be interpreted with caution, because disease activity in TAK may decrease as a result of continued GC therapy over time. In contrast to the positive trends observed in GCA, the RCT of abatacept did not show any signs of efficacy in TAK. ${ }^{67}$ Lower quality evidence from uncontrolled prospective and retrospective case series exists for the use of conventional immunosuppressive agents such as MTX, leflunomide, mycophenolate mofetil, azathioprine and cyclophosphamide in TAK. ${ }^{112-117}$ Since TAK targets primarily women with childbearing potential and is a chronic and usually not acutely life threatening disease (unlike AAV), the use of cyclophosphamide should be limited to patients where other treatments have failed or are not tolerated. There is no high-quality evidence showing superiority of biologicals over conventional disease modifying anti-rheumatic drugs (DMARDs) in TAK.

Despite this overall low LoE, we recommend considering adjunctive treatment with conventional immunosuppressive drugs at diagnosis of TAK. A TNF-inhibitor or TCZ can be used as second line agents in case of relapsing disease. The choice of a specific immunosuppressive agent should be based on patient comorbidities or contraindications. GCs should be tapered to the lowest possible dose during treatment with immunosuppressive agents. Because good-quality data on long-term treatment of TAK are lacking, the duration of treatment must be decided on an individual basis. One study indicated that relapse risk is particularly high during the first 5 years following diagnosis. ${ }^{92}$

In case of major relapse (either with signs or symptoms of ischaemia or progressive vascular inflammation) we recommend reinstitution or dose escalation of GC therapy as recommended for new onset disease. For minor relapses we recommend an increase in GC dose to at least the last effective dose. Initiation or modification of adjunctive therapy should be considered particularly after recurrent disease relapses

There are no studies specifically addressing the treatment of relapse in LVV. Even larger cohort studies on relapses in GCA often lack detailed information on treatment of the relapse (GC dose, tapering, initiation of adjunctive treatment, etc). ${ }^{5051}$ Protocols for relapse treatment differ among RCTs and the heterogeneous study designs and adjunctive therapies do not allow for robust conclusions regarding which of the different strategies is the best.

Major relapses impose the risk of subsequent organ damage due to ischaemia and/or progressive vascular inflammation (eg, progressive large vessel stenosis) and should therefore be treated like new-onset disease with high dose GC (initial dose 40-60 mg/day) as outlined above (recommendations 3 and 4). In case of a minor relapse (eg, recurring isolated polymyalgia rheumatica (PMR) symptoms), we recommend an increase of the daily GCs dose either to the last effective dose or to 5-15 $\mathrm{mg}$ above this dose, the latter being common practice in many centres.

Disease relapses in LVV are most commonly but not always accompanied by an increase of ESR and CRP. ${ }^{49} 5152118$ In the
Box 1 Research agenda

A. Diagnosis and classification

- Develop data-driven classification criteria for large vessel vasculitis (LVV).

- Develop data-driven diagnostic criteria for LVV.

- Develop data-driven definitions for disease activity states (remission, response, relapse) and standardisation of outcome measures used in trials for LVV.

- Develop data-driven definitions of disease subtypes of importance in giant cell arteritis (GCA).

- Identify reliable biomarkers and risk factors for relapsing disease and future vascular complications.

- Identify reliable biomarkers to assess subclinical disease activity and monitor treatment response.

- Investigate the use of the different imaging techniques for vascular activity and damage assessment and follow-up of patients with LVV, as outlined in the EULAR recommendations on imaging in LVV2.

- Investigate the role of ultrasound for guiding temporal artery biopsy.

\section{B. Treatment}

- Evaluate the effects of a mechanism-based approach to therapy (eg, IL-12/Interferon-gamma inhibition vs IL-6 inhibition).

- Identify how rapidly glucocorticoids (GCs) can be tapered in LVV.

- Identify if GC dosing based on body-weight or body surface area is superior to standard dosing.

- Investigate the effect of MTX, tocilizumab, or other adjunctive therapies and combination therapy on the development of future vascular complications in LVV.

- Investigate the optimal duration of treatment including tapering strategies and dosing (eg, higher MTX doses).

- Investigate the value of conventional (eg, leflunomide), biological and other targeted DMARDs for treatment of all forms of LVV.

- Investigate the role of anti-platelet therapy in LVV.

- Investigate predictors of response to therapy in LVV.

\section{Long-term outcome and biomarkers}

- Identify biomarkers which are independent of IL-6 (which could reflect response to anti-IL6 therapy).

- Identify biomarkers to predict drug toxicity.

- Identify predictors for good response, remission or relapse.

- Investigate the value of screening for aortic dilatation regarding the prevention of complications (ie, aortic dissection or aortic ruptures).

- Define and validate patient-reported outcomes in LVV.

- Investigate the role of immunosuppressive agents in other forms of LVV such as isolated aortitis or IgG4 related periaortitis.

absence of symptoms of LVV, a rise of ESR or CRP should not automatically prompt an immediate escalation of immunosuppressive therapy. Infections should be ruled out first. If repeated measurements confirm a substantial elevation of ESR and CRP and if there is no evidence for another cause of the inflammatory response, large vessel imaging should be considered. In the presence of less specific symptoms (eg, diffuse headache) in patients with normal inflammatory markers, 
imaging (ultrasound, MRI or PET-CT) may be helpful. ${ }^{2}$ However, signals of vessel wall inflammation on imaging may persist even in complete clinical remission. ${ }^{16} 119$ At present, it is unknown if such residual activity represents true active disease or remodelling. Therefore, such imaging findings observed during follow-up have to be interpreted with caution considering the disease course of the individual patient and by comparing them to imaging findings previously obtained. ${ }^{2}$

As outlined in recommendation 5, we recommend adjunctive GC sparing therapy (if not already begun at disease onset) or a modification (dose escalation or switch to another agent) of an already existing GC-sparing therapy in relapsing patients in order to improve long-term disease control. So far, there are no RCTs that have specifically focused on the adjunctive treatment of relapses. However, the GiACTA trial included 132 relapsing patients and TCZ was superior to GC monotherapy in this situation. ${ }^{38}$ All three RCTs of MTX in GCA included patients with new onset disease only. However, patients who received MTX had a 50\% lower risk $(p=0.02)$ of developing a second relapse in a meta-analysis, thus providing evidence for the efficacy of MTX after a first relapse. Other agents have either not been studied prospectively or showed no signs of efficacy in relapsing GCA.

In relapsing TAK despite treatment with GC plus a conventional immunosuppressive agent, a TNF-inhibitor or TCZ can be used as second line agent (see also recommendation 6).

Antiplatelet or anticoagulant therapy should not be routinely used for treatment of LVV unless it is indicated for other reasons (eg, coronary heart disease, cerebrovascular disease, etc). In special situations such as vascular ischaemic complications or high risk of cardiovascular disease, these might be considered on an individual basis

Patients with GCA are at an increased risk of developing cardiovascular and cerebrovascular events. ${ }^{120} 121$ The original EULAR recommendation to use aspirin prophylactically in GCA was based on data from two retrospective studies showing that patients who received low-dose aspirin before or at the time of diagnosis of GCA may have reduced rates of vision loss or stroke, although the number of events was low in these cohorts. ${ }^{122123}$ However, two more recent cohort studies and a meta-analysis did not confirm a protective effect of aspirin in GCA. ${ }^{124-126}$ Balancing the potential protective effect (which is unknown) of aspirin against its potential harm (such as bleeding), ${ }^{127}$ we decided to change the original statement and now recommend that antiplatelet or anticoagulant therapy should not be routinely prescribed unless they are indicated for other reasons (eg, coronary heart disease, cerebrovascular disease, etc).

A significantly decreased risk of ischaemic events was reported from a single cohort of 41 TAK patients using antiplatelet therapy. ${ }^{128}$ In view of the low LoE, a vascular team should decide on the use of anti-platelet therapy in TAK on an individual basis taking the degree of vessel stenosis and other risk factors into account.

In LVV, elective endovascular interventions or reconstructive surgery should be performed during stable remission. However, arterial vessel dissection or critical vascular ischaemia requires urgent referral to a vascular team

Interventional or surgical therapy is indicated if a vascular lesion that persists despite medical therapy is either symptomatic (such as a peripheral artery limb stenosis causing claudication) or is associated with an increased risk of future complications (such as rapid progression of an aortic aneurysm). The method of choice for vascular interventions in patients with LVV depends on the anatomic location of the vascular damage, timing (elective vs emergency) and other factors.

Undertaking surgical interventions in patients with active disease is associated with an increased risk of complications and lower patency rates. ${ }^{129-132}$ Procedures should preferably be performed only during stable control of inflammation, except for emergency indications such as critical ischaemia, neurological complications such as stroke or aneurysm dissection. Otherwise, interventional and surgical vascular therapy follows the same principles as in patients without vasculitis. ${ }^{133134}$ Given the complexity of LVV, patients selected for interventional or surgical therapy should be managed in collaboration with a multidisciplinary team (the exact constituency will vary, but could include vascular radiologists, vascular surgeons, neurologists and rheumatologists).

Regular follow-up and monitoring of disease activity is recommended in patients with LVV, primarily based on symptoms, clinical findings and ESR/CRP levels

There are no data available to guide long-term follow-up of patients with GCA or TAK. In view of the high frequency of relapses and the potential harm resulting from relapse-related vessel and organ damage, routine follow-up visits could be scheduled every 1-3 months during the first year and in 3-6 months intervals afterwards. In patients with relapsefree remission, annual follow-up under shared care between rheumatologists and primary care can be considered. As late relapses can occur and the incidence of structural vascular lesions in GCA increases after 5 years from diagnosis, ${ }^{49} 50135$ long-term follow-up of patients with GCA that remain asymptomatic can be scheduled on an individual patient basis.

Visits should include clinical monitoring and measurement of ESR and CRP. Routine imaging for activity assessment is not recommended for patients in clinical and biochemical remission, but may be used for long-term monitoring of structural damage, particularly vessel stenosis, dilatation and/or aneurysms. ${ }^{2}$ Methods and frequency of imaging should be decided on an individual basis. ${ }^{2}$ LVV-specific patient-reported outcome instruments for use in clinical practice are not available, ${ }^{38136-138}$ and should be the subject of future research.

\section{DISCUSSION}

Since the first EULAR recommendations on the management of LVV were published, high-quality diagnostic studies and several RCTs have expanded our knowledge about these complex diseases and allowed a significant update of the original recommendations. In view of new research questions to be addressed, improvements in SOPs and methodology for the development of EULAR recommendations, ${ }^{3}$ we undertook two completely new SLRs without time limits. Therefore, this update represents a new set of recommendations rather than a simple revision. While the majority of the original recommendations addressed LVV in general, new data allowed us to offer separate recommendations for GCA and TAK at least for some key areas of management. In GCA, disease subsets with only cranial, only extracranial or cranial plus extracranial arteritis have been described. High-quality evidence to guide differential management of these subtypes is yet lacking. Therefore, 
all recommendations on GCA management inhere refer to all subtypes of GCA.

For this update, we have made substantial alterations, including the introduction of overarching principles and new recommendations on early diagnosis, multidisciplinary management and relapse treatment.

In conclusion, we substantially revised the original recommendations for the management of LVV. Despite progress over the past 10 years, we acknowledge that many recommendations are still consensus-based. However, despite the low-LoE, the level of agreement for each recommendation was consistently high among the task force members. We encourage clinicians to implement these recommendations into their clinical practice in order to effectively manage LVV and to improve the patients' quality of care.

\section{Author affiliations}

'Department of Internal Medicine, Rheumatology and Immunology, Medius Kliniken, University of Tübingen, Kirchheim-Teck, Germany

${ }^{2}$ Rheumatology Department, Centro Hospitalar do Baixo Vouga E.P.E, Aveiro, Portugal

${ }^{3}$ Rheumatology, Fondazione IRCCS Policlinico San Matteo, University of Pavia, Pavia, Italy

${ }^{4}$ Department of Rheumatology and Immunology, University Hospital Charité, Berlin, Germany

Internal Medicine, Centre Hospitalier Universitaire de Caen, Caen, BasseNormandie, France

${ }^{6}$ Rheumatology and Clinical Immunology, UMCG, Groningen, The Netherlands 'Leicester, UK

${ }^{8}$ Department of Autoimmune Diseases, Hospital Clinic, University of Barcelona, Institut d'Investigacions Biomèdiques August Pi I Sunyer (IDIBAPS), Barcelona, Spain ${ }^{9}$ Rheumatology, Southend Hospital NHS Trust, Westcliff-on-sea, UK

${ }^{10}$ Rheumatology, Medical University Graz, Graz, Austria

${ }^{11}$ Rheumatology, Hospital of Bruneck, Bruneck, Italy

${ }^{12}$ Division of Rheumatology, Department of Internal Medicine, Istanbul University Cerrahpasa Faculty of Medicine, Istanbul, Turkey

${ }^{13}$ Department of Internal Medicine, Rheumatology and Immunology, Medus Klinken, Karl-Albrechts-Universität Tübingen, Kirchheim-Teck, Germany

${ }^{14}$ Hospital Saint-Louis, University Paris Diderot, Paris, France

${ }^{15}$ Ophthalmology, University Hospitals Birmingham, Birmingham, UK

${ }^{16}$ Neurometabolism, Institute of Metabolism and Systems Research, University of

Birmingham, Birmingham, UK

${ }^{17}$ Rheumatology, Norfolk and Norwich University Hospital, Norwich, UK

${ }^{18}$ Rheumatology, Hospital de Santa Maria - CHLN, Lisbon Academic Medical Centre, Lisbon, Portugal

${ }^{19}$ Rheumatology Research Unit; Instituto de Medicina Molecular, Instituto de Medicina Molecular, Lisboa, Portugal

${ }^{20}$ Arcispedale S Maria Nuova, Reggio Emilia, Italy

${ }^{21}$ Stroke and Neurocritical Care, GLB Hospitals and Acute Stroke Centers, Chennai, India

${ }^{22}$ Rheumatology, Peking Union Medical College Hospital, Beijing, China

${ }^{23}$ University of Iceland, Reykjavik, Iceland

${ }^{24}$ Department of Rheumatology, Skåne University Hospital, Malmö, Sweden

${ }^{25}$ Medical Centre for Rheumatology Berlin-Buch, Immanuel Krankenhaus Berlin,

Berlin, Germany

${ }^{26}$ Rheumatology and Clinical Immunology / Allerg, University Hospital (Inselspital),

Bern, Switzerland

${ }^{27}$ Norwich Medical School, Bob Champion Research and Education Building,

University of East Anglia, Norwich, UK

${ }^{28}$ Steyning, UK

${ }^{29}$ Nuffield Department of Orthopaedics, Rheumatology and Musculoskeletal Science (NDORMs), University of Oxford, Oxford, UK

Correction notice This article has been corrected since it published Online First. The third affiliations has been updated and the author's names for Maria C Cid and Wolfgang Schmidt have been corrected.

Acknowledgements The authors wish to thank the librarians Chiara Rebuffi, Grant Office and Scientific Documentation centre, Fondazione IRCCS Policlinico San Matteo, Pavia, Italy and Helena Donato, Documentation Unit, Centro Hospitalar e Universitário de Coimbra, Coimbra, Portugal, for advice and assistance during the SLR.

Contributors AA and SM conducted the SLR. RL provided substantial methodological advice. BH drafted the first version of the manuscript and subsequent revisions. All authors were involved in the formulation and discussion of the recommendations, reviewed the manuscript and made extensive comments and changes to it. The final version of the manuscript was approved by all authors.

Funding The authors have not declared a specific grant for this research from any funding agency in the public, commercial or not-for-profit sectors.

Competing interests EB received consultancies from Roche (payed to the University Medical Center Groningen). FB received grants from Horizon and Mundipharma and speaker fees and/or consultancies from Horizon, Mundipharma, Roche and Sanofi. HB received a grant and speaker fees from Roche. BD received consultancies and/or speaker fees from BMS, Chugai, GSK and Roche. CD received and grant from Celgene and speaker fees and/or consultancies from Abbvie, BMS, Lilly, MSD, Pfizer, Novartis, UCB, Roche and Sanofi. BH received speaker fees and/ or consultancies from Abbvie, Boehringer, Chugai, Celgene, MSD, Pfizer, Novartis and Roche. SM received speaker fees and consultancies from Roche and Chugai. WS received a grant from Roche and speaker fees and consultancies from Chugai, GSG, Novartis, Roche and Sanofi. CT received a grant from BMS and speaker fees and/or consultancies from Abbvie, BMS, Pfizer and Roche. PV received a grant for conducting an RCT in GCA from Roche. All other authors have no competing interests.

Patient consent for publication Not required.

Provenance and peer review Not commissioned; externally peer reviewed.

\section{ORCID iDs}

Bernhard Hellmich http://orcid.org/0000-0002-8014-1801

Christian Dejaco http://orcid.org/0000-0002-0173-0668

Gulen Hatemi http://orcid.org/0000-0002-1952-1135

Chetan Mukhtyar http://orcid.org/0000-0002-9771-6667

\section{REFERENCES}

1 Mukhtyar C, Guillevin L, Cid MC, et al. EULAR recommendations for the management of large vessel vasculitis. Ann Rheum Dis 2009;68:318-23.

2 Dejaco C, Ramiro S, Duftner C, et al. EULAR recommendations for the use of imaging in large vessel vasculitis in clinical practice. Ann Rheum Dis 2018:77:636-43.

3 van der Heijde D, Aletaha D, Carmona L, et al. 2014 update of the EULAR standardised operating procedures for EULAR-endorsed recommendations. Ann Rheum Dis 2015:74:8-13.

4 AGREE. Available: http://www. agreetrust.org/wp-content/uploads/2013/10/AGREEII-Users-Manual-and-23-item-Instrument_2009_UPDATE_2013.pdf

5 Monti S, Agueda AF, Luqmani R, et al. Systematic literature review Informing the 2018 update of the EULAR recommendations for the management of large vessel vasculitis: focus on giant cell arteritis. RMD open 2019.

6 Agueda A, Monti S, Luqmani R, et al. Management of Takayasu arteritis: a systematic review Informing the 2018 update of the EULAR recommendations for the management of large vessel vasculitis. RMD open 2019.

7 Hellmich B, Flossmann O, Gross WL, et al. EULAR recommendations for conducting clinical studies and/or clinical trials in systemic vasculitis: focus on anti-neutrophil cytoplasm antibody-associated vasculitis. Ann Rheum Dis 2007;66:605-17.

8 Jennette JC, Falk RJ, Bacon PA, et al. 2012 revised international chapel Hill consensus Conference Nomenclature of vasculitides. Arthritis Rheum 2013;65:1-11.

9 Diamantopoulos AP, Haugeberg G, Lindland A, et al. The fast-track ultrasound clinic for early diagnosis of giant cell arteritis significantly reduces permanent visual impairment: towards a more effective strategy to improve clinical outcome in giant cell arteritis? Rheumatology 2016;55:66-70.

10 Patil P, Williams M, Maw WW, et al. Fast track pathway reduces sight loss in giant cell arteritis: results of a longitudinal observational cohort study. Clin Exp Rheumatol 2015:33(Suppl 89):S-103-6.

11 Monti S, Floris A, Ponte C, et al. The use of ultrasound to assess giant cell arteritis: review of the current evidence and practical guide for the rheumatologist. Rheumatology 2018;57:227-35

12 González-Gay MA, Blanco R, Rodríguez-Valverde V, et al. Permanent visual loss and cerebrovascular accidents in giant cell arteritis: predictors and response to treatment. Arthritis Rheum 1998:41:1497-504.

13 Luqmani R, Lee E, Singh S, et al. The role of ultrasound compared to biopsy of temporal arteries in the diagnosis and treatment of giant cell arteritis (TABUL): a diagnostic accuracy and cost-effectiveness study. Health Technol Assess 2016:20:1-238

14 Hauenstein C, Reinhard M, Geiger J, et al. Effects of early corticosteroid treatment on magnetic resonance imaging and ultrasonography findings in giant cell arteritis, Rheumatology 2012;51:1999-2003.

15 Maleszewski JJ, Younge BR, Fritzlen JT, et al. Clinical and pathological evolution of giant cell arteritis: a prospective study of follow-up temporal artery biopsies in 40 treated patients. Mod Pathol 2017;30:788-96.

16 Blockmans D, de Ceuninck L, Vanderschueren S, et al. Repetitive 18Ffluorodeoxyglucose positron emission tomography in giant cell arteritis: a prospective study of 35 patients. Arthritis Rheum 2006;55:131-7.

17 Ypsilantis E, Courtney ED, Chopra N, et al. Importance of specimen length during temporal artery biopsy. Br J Surg 2011;98:1556-60. 
18 Achkar AA, Lie JT, Hunder GG, et al. How does previous corticosteroid treatment affect the biopsy findings in giant cell (temporal) arteritis? Ann Intern Med 1994;120:987-92.

19 Ball EL, Walsh SR, Tang TY, et al. Role of ultrasonography in the diagnosis of temporal arteritis. Br J Surg 2010;97:1765-71.

20 Duftner C, Dejaco C, Sepriano A, et al. Imaging in diagnosis, outcome prediction and monitoring of large vessel vasculitis: a systematic literature review and meta-analysis Informing the EULAR recommendations. RMD Open 2018;4:e000612.

21 Bley TA, Reinhard M, Hauenstein C, et al. Comparison of duplex sonography and high-resolution magnetic resonance imaging in the diagnosis of giant cell (temporal) arteritis. Arthritis Rheum 2008;58:2574-8.

22 Germano G, Muratore F, Cimino L, et al. Is colour duplex sonography-guided temporal artery biopsy useful in the diagnosis of giant cell arteritis? A randomized study. Rheumatology 2015;54:400-4.

23 Hernández-Rodríguez J, Murgia G, Villar I, et al. Description and validation of histological patterns and proposal of a dynamic model of inflammatory infiltration in giant-cell arteritis. Medicine 2016;95:e2368.

24 Armstrong AT, Tyler WB, Wood GC, et al. Clinical importance of the presence of giant cells in temporal arteritis. J Clin Pathol 2008;61:669-71.

25 Breuer GS, Nesher R, Reinus K, et al. Association between histological features in temporal artery biopsies and clinical features of patients with giant cell arteritis. Isr Med Assoc J 2013;15:271-4.

26 Cavazza A, Muratore F, Boiardi L, et al. Inflamed temporal artery: histologic findings in 354 biopsies, with clinical correlations. Am J Surg Pathol 2014;38:1360-70.

27 Restuccia G, Cavazza A, Boiardi L, et al. Small-vessel vasculitis surrounding an uninflamed temporal artery and isolated vasa vasorum vasculitis of the temporal artery: two subsets of giant cell arteritis. Arthritis Rheum 2012;64:549-56.

28 Chatelain D, Duhaut P, Schmidt J, et al. Pathological features of temporal arteries in patients with giant cell arteritis presenting with permanent visual loss. Ann Rheum Dis 2009;68:84-8.

29 Kaiser M, Weyand CM, Björnsson J, et al. Platelet-derived growth factor, intimal hyperplasia, and ischemic complications in giant cell arteritis. Arthritis Rheum 1998;41:623-33.

30 Makkuni D, Bharadwaj A, Wolfe K, et al. Is intimal hyperplasia a marker of neuroophthalmic complications of giant cell arteritis? Rheumatology 2008;47:488-90.

31 Muratore F, Boiardi L, Cavazza A, et al. Correlations between histopathological findings and clinical manifestations in biopsy-proven giant cell arteritis. J Autoimmun 2016;69:94-101

32 Quinn EM, Kearney DE, Kelly J, et al. Temporal artery biopsy is not required in all cases of suspected giant cell arteritis. Ann Vasc Surg 2012;26:649-54.

33 Restuccia G, Boiardi L, Cavazza A, et al. Flares in biopsy-proven giant cell arteritis in northern Italy: characteristics and predictors in a long-term follow-up study. Medicine 2016;95:e3524.

34 ter Borg EJ, Haanen HCM, Seldenrijk CA. Relationship between histological subtypes and clinical characteristics at presentation and outcome in biopsy-proven temporal arteritis. Identification of a relatively benign subgroup. Clin Rheumatol 2007;26:529-32.

35 Schmidt D, Löffler KU, arteritis T. Temporal arteritis. Comparison of histological and clinical findings. Acta Ophthalmol 1994;72:319-25.

36 Naderi N, Mohammad AJ, Turesson C. Large vessel involvement in biopsy-proven giant cell arteritis: incidence, distribution, and predictors. Scand J Rheumatol 2017:46:215-21.

37 Parikh M, Miller NR, Lee AG, et al. Prevalence of a normal C-reactive protein with an elevated erythrocyte sedimentation rate in biopsy-proven giant cell arteritis. Ophthalmology 2006;113:1842-5.

38 Stone JH, Tuckwell K, Dimonaco S, et al. Trial of tocilizumab in giant-cell arteritis. $N$ Engl J Med 2017;377:317-28.

39 Raine C, Stapleton PP, Merinopoulos D, et al. A 26-week feasibility study comparing the efficacy and safety of modified-release prednisone with immediate-release prednisolone in newly diagnosed cases of giant cell arteritis. Int J Rheum Dis 2018:21:285-91.

40 Mazlumzadeh M, Hunder GG, Easley KA, et al. Treatment of giant cell arteritis using induction therapy with high-dose glucocorticoids: a double-blind, placebo-controlled, randomized prospective clinical trial. Arthritis Rheum 2006:54:3310-8

41 Chevalet $\mathrm{P}$, Barrier JH, Pottier $\mathrm{P}$, et al. A randomized, multicenter, controlled trial using intravenous pulses of methylprednisolone in the initial treatment of simple forms of giant cell arteritis: a one year followup study of 164 patients. J Rheumatol 2000;27:1484-91.

42 Kyle V, Hazleman BL. Treatment of polymyalgia rheumatica and giant cell arteritis. I. steroid regimens in the first two months. Ann Rheum Dis 1989;48:658-61.

43 Les I, Pijoan Jl, Rodriguez-Alvarez R, et al. Effectiveness and safety of medium-dose prednisone in giant cell arteritis: a retrospective cohort study of 103 patients. Clin Exp Rheumatol 2015;33(Suppl 89):S-90-7.

44 Buttgereit F, da Silva JAP, Boers M, et al. Standardised Nomenclature for glucocorticoid dosages and glucocorticoid treatment regimens: current questions and tentative answers in rheumatology. Ann Rheum Dis 2002;61:718-22.
45 Sanden S, Tripmacher R, Weltrich R, et al. Glucocorticoid dose dependent downregulation of glucocorticoid receptors in patients with rheumatic diseases. $J$ Rheumatol 2000;27:1265-70.

46 Schottelius A, Wedel S, Weltrich $\mathrm{R}$, et al. Higher expression of glucocorticoid receptor in peripheral mononuclear cells in inflammatory bowel disease. Am J Gastroenterol 2000;95:1994-9.

47 Chan CC, Paine M, O'Day J. Steroid management in giant cell arteritis. $\mathrm{Br}$ J Ophthalmol 2001:85:1061-4.

48 Hayreh SS, Zimmerman B, Kardon RH. Visual improvement with corticosteroid therapy in giant cell arteritis. Report of a large study and review of literature. Acta Ophthalmol Scand 2002;80:355-67.

49 Alba MA, García-Martínez A, Prieto-González S, et al. Relapses in patients with giant cell arteritis: prevalence, characteristics, and associated clinical findings in a longitudinally followed cohort of 106 patients. Medicine 2014;93:194-201.

50 Kermani TA, Warrington KJ, Cuthbertson D, et al. Disease relapses among patients with giant cell arteritis: a prospective, longitudinal cohort study. J Rheumatol 2015;42:1213-7.

51 Labarca C, Koster MJ, Crowson CS, et al. Predictors of relapse and treatment outcomes in biopsy-proven giant cell arteritis: a retrospective cohort study. Rheumatology 2016;55:347-56.

52 Martinez-Lado L, Calviño-Díaz C, Piñeiro A, et al. Relapses and recurrences in giant cell arteritis: a population-based study of patients with biopsy-proven disease from northwestern Spain. Medicine 2011;90:186-93.

53 Liozon E, Roblot P, Paire D, et al. Anticardiolipin antibody levels predict flares and relapses in patients with giant-cell (temporal) arteritis. A longitudinal study of 58 biopsy-proven cases. Rheumatology 2000;39:1089-94.

54 Proven A, Gabriel SE, Orces C, et al. Glucocorticoid therapy in giant cell arteritis: duration and adverse outcomes. Arthritis Rheum 2003:49:703-8.

55 Nesher G, Nesher R, Mates M, et al. Giant cell arteritis: intensity of the initial systemic inflammatory response and the course of the disease. Clin Exp Rheumatol 2008;26(3 Suppl 49):\$30-4.

56 Hernández-Rodríguez J, García-Martínez A, Casademont J, et al. A strong initial systemic inflammatory response is associated with higher corticosteroid requirements and longer duration of therapy in patients with giant-cell arteritis. Arthritis Rheum 2002:47:29-35.

57 Hachulla E, Boivin V, Pasturel-Michon U, et al. Prognostic factors and long-term evolution in a cohort of 133 patients with giant cell arteritis. Clin Exp Rheumatol 2001;19:171-6.

58 Graham E, Holland A, Avery A, et al. Prognosis in giant-cell arteritis. In: British medical journal (clinical research. . 282(6260, 1981: 282. 269-71.

59 Jamilloux Y, Liozon E, Pugnet G, et al. Recovery of adrenal function after longterm glucocorticoid therapy for giant cell arteritis: a cohort study. PLoS One 2013:8:e68713.

60 Broder MS, Sarsour K, Chang E, et al. Corticosteroid-related adverse events in patients with giant cell arteritis: a claims-based analysis. Semin Arthritis Rheum 2016:46:246-52.

61 Chandran A, Udayakumar PD, Kermani TA, et al. Glucocorticoid usage in giant cell arteritis over six decades (1950 to 2009). Clin Exp Rheumatol 2015;33(Suppl 89):S98-102.

62 Delecoeuillerie G, Joly P, Cohen de Lara A, et al. Polymyalgia rheumatica and temporal arteritis: a retrospective analysis of prognostic features and different corticosteroid regimens (11 year survey of 210 patients). Ann Rheum Dis 1988:47:733-9.

63 Wilson JC, Sarsour K, Collinson N, et al. Incidence of outcomes potentially associated with corticosteroid therapy in patients with giant cell arteritis. Semin Arthritis Rheum 2017; 46:650-6

64 Wilson JC, Sarsour K, Collinson N, et al. Serious adverse effects associated with glucocorticoid therapy in patients with giant cell arteritis (GCA): a nested casecontrol analysis. Semin Arthritis Rheum 2017:46:819-27.

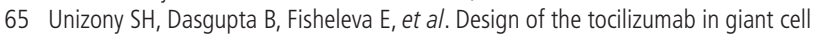
arteritis trial. Int J Rheumatol 2013:2013:1-10.

66 Nakaoka Y, Isobe M, Takei S, et al. Efficacy and safety of tocilizumab in patients with refractory Takayasu arteritis: results from a randomised, double-blind, placebocontrolled, phase 3 trial in Japan (the TAKT study). Ann Rheum Dis 2018;77:348-54

67 Langford CA, Cuthbertson D, Ytterberg SR, et al. A randomized, double-blind trial of abatacept (CTLA-4lg) for the treatment of Takayasu arteritis. Arthritis Rheumatol 2017;69:846-53.

68 Strehl C, Bijlsma JWJ, de Wit M, et al. Defining conditions where long-term glucocorticoid treatment has an acceptably low level of harm to facilitate implementation of existing recommendations: viewpoints from an EULAR Task Force. Ann Rheum Dis 2016;75:952-7.

69 Strangfeld A, Richter A, Siegmund B, et al. Risk for lower intestinal perforations in patients with rheumatoid arthritis treated with tocilizumab in comparison to treatment with other biologic or conventional synthetic DMARDs. Ann Rheum Dis 2017:76:504-10.

70 Villiger PM, Adler S, Kuchen S, et al. Tocilizumab for induction and maintenance of remission in giant cell arteritis: a phase 2, randomised, double-blind, placebocontrolled trial. The Lancet 2016;387:1921-7. 
71 Weyand CM, Goronzy JJ. Immune mechanisms in medium and large-vessel vasculitis. Nat Rev Rheumatol 2013;9:731-40.

72 Hoffman GS, Cid MC, Hellmann DB, et al. A multicenter, randomized, double-blind, placebo-controlled trial of adjuvant methotrexate treatment for giant cell arteritis. Arthritis \& Rheumatism 2002;46:1309-18.

73 Spiera RF, Mitnick HJ, Kupersmith M, et al. A prospective, double-blind, randomized, placebo controlled trial of methotrexate in the treatment of giant cell arteritis (GCA) Clin Exp Rheumatol 2001;19:495-501.

74 Jover JA, Hernández-García C, Morado IC, et al. Combined treatment of giant-cell arteritis with methotrexate and prednisone. A randomized, double-blind, placebocontrolled trial. Ann Intern Med 2001;134:106-14.

75 Mahr AD, Jover JA, Spiera RF, et al. Adjunctive methotrexate for treatment of giant cell arteritis: an individual patient data meta-analysis. Arthritis Rheum 2007:56:2789-97.

76 Leon L, Rodriguez-Rodriguez L, Freites D, et al. Long-term continuation of methotrexate therapy in giant cell arteritis patients in clinical practice. Clin Exp Rheumatol 2017;35 Suppl 103:165-70.

77 Evans J, Steel L, Borg F, et al. Long-term efficacy and safety of tocilizumab in giant cell arteritis and large vessel vasculitis. RMD Open 2016;2:e000137.

78 Rigby WFC, Lampl K, Low JM, et al. Review of routine laboratory monitoring for patients with rheumatoid arthritis receiving biologic or Nonbiologic DMARDs. Int J Rheumatol 2017;2017:1-15.

79 Langford CA, Cuthbertson D, Ytterberg SR, et al. A randomized, double-blind trial of abatacept (CTLA-4Ig) for the treatment of giant cell arteritis. Arthritis Rheumatol 2017;69:837-45.

80 Conway R, O'Neill L, O'Flynn E, et al. Ustekinumab for the treatment of refractory giant cell arteritis. Ann Rheum Dis 2016.

81 Quartuccio L, Maset M, De Maglio G, et al. Role of oral cyclophosphamide in the treatment of giant cell arteritis. Rheumatology 2012:51:1677-86.

82 Loock J, Henes J, Kötter I, et al. Treatment of refractory giant cell arteritis with cyclophosphamide:a retrospective analysis of 35 patients from three centres. Clin Exp Rheumatol 2012;30(1 Suppl 70):S70-6.

83 de Boysson H, Boutemy J, Creveuil C, et al. Is there a place for cyclophosphamide in the treatment of giant-cell arteritis? A case series and systematic review. Semin Arthritis Rheum 2013:43:105-12.

84 Adizie T, Christidis D, Dharmapaliah C, et al. Efficacy and tolerability of leflunomide in difficult-to-treat polymyalgia rheumatica and giant cell arteritis: a case series. Int $J$ Clin Pract 2012;66:906-9.

85 Hoffman GS, Cid MC, Rendt-Zagar KE, et al. Infliximab for maintenance of glucocorticosteroid-induced remission of giant cell arteritis: a randomized trial. Ann Intern Med 2007;146:621-30.

86 Martínez-Taboada VM, Rodríguez-Valverde V, Carreño L, et al. A double-blind placebo controlled trial of etanercept in patients with giant cell arteritis and corticosteroid side effects. Ann Rheum Dis 2008;67:625-30.

87 Seror R, Baron G, Hachulla E, et al. Adalimumab for steroid sparing in patients with giant-cell arteritis: results of a multicentre randomised controlled trial. Ann Rheum Dis 2014;73:2074-81.

88 Schaufelberger C, Andersson R, Nordborg E. No additive effect of cyclosporin A compared with glucocorticoid treatment alone in giant cell arteritis: results of an open, controlled, randomized study. Rheumatology 1998;37:464-5.

89 Schaufelberger C, Möllby H, Uddhammar A, et al. No additional steroid-sparing effect of cyclosporine A in giant cell arteritis. Scand J Rheumatol 2006;35:327-9.

90 Ly KH, Dalmay F, Gondran G, et al. Steroid-sparing effect and toxicity of dapsone treatment in giant cell arteritis: a single-center, retrospective study of 70 patients. Medicine 2016;95:e4974.

91 Ohigashi $\mathrm{H}$, Haraguchi $\mathrm{G}$, Konishi M, et al. Improved prognosis of Takayasu arteritis over the past decade--comprehensive analysis of 106 patients. Circ $」$ 2012;76:1004-11.

92 Comarmond C, Biard L, Lambert M, et al. Long-term outcomes and prognostic factors of complications in Takayasu arteritis: a multicenter study of 318 patients. Circulation 2017;136:1114-22.

93 Maksimowicz-McKinnon K, Clark TM, Hoffman GS. Limitations of therapy and a guarded prognosis in an American cohort of Takayasu arteritis patients. Arthritis Rheum 2007;56:1000-9.

94 Bicakcigil M, Aksu K, Kamali S, et al. Takayasu's arteritis in Turkey - clinical and angiographic features of 248 patients. Clin Exp Rheumatol 2009;27(1 Suppl 52):S59-64.

95 Zhou J, Chen Z, Li J, et al. The efficacy of tocilizumab for the treatment of Chinese Takayasu's arteritis. Clin Exp Rheumatol 2017;35 Suppl 103:171-5.

96 Nakaoka Y, Higuchi K, Arita Y, et al. Tocilizumab for the treatment of patients with refractory Takayasu arteritis. Int Heart J 2013;54:405-11.

97 Loricera J, Blanco R, Hernández JL, et al. Tocilizumab in giant cell arteritis: multicenter open-label study of 22 patients. Semin Arthritis Rheum 2015:44:717-23.

98 Abisror N, Mekinian A, Lavigne C, et al. Tocilizumab in refractory Takayasu arteritis: a case series and updated literature review. Autoimmunity Reviews 2013;12:1143-9
99 Tombetti E, Franchini S, Papa M, et al. Treatment of refractory Takayasu arteritis with tocilizumab: 7 Italian patients from a single referral center. J Rheumatol 2013;40:2047-51.

100 Goel R, Danda D, Kumar S, et al. Rapid control of disease activity by tocilizumab in 10 'difficult-to-treat' cases of Takayasu arteritis. Int J Rheum Dis 2013;16:754-61.

101 Hoffman GS, Merkel PA, Brasington RD, et al. Anti-tumor necrosis factor therapy in patients with difficult to treat Takayasu arteritis. Arthritis Rheum 2004:50:2296-304.

102 Gudbrandsson B, Molberg Øyvind, Palm Øyvind. TNF inhibitors appear to inhibit disease progression and improve outcome in Takayasu arteritis; an observational, population-based time trend study. Arthritis Res Ther 2017;19.

103 Novikov PI, Smitienko IO, Moiseev SV. Tumor necrosis factor alpha inhibitors in patients with Takayasu's arteritis refractory to standard immunosuppressive treatment: cases series and review of the literature. Clin Rheumatol 2013:32:1827-32.

104 Comarmond C, Plaisier E, Dahan K, et al. Anti TNF- $\alpha$ in refractory Takayasu's arteritis: cases series and review of the literature. Autoimmun Rev 2012;11:678-84.

105 Schmidt J, Kermani TA, Kirstin Bacani A, Bacani AK, et al. Tumor necrosis factor inhibitors in patients with Takayasu arteritis: experience from a referral center with long-term follow-up. Arthritis Care Res 2012;64:n/a-83.

106 Molloy ES, Langford CA, Clark TM, et al. Anti-tumour necrosis factor therapy in patients with refractory Takayasu arteritis: long-term follow-up. Annals of the Rheumatic Diseases 2008;67:1567-9.

107 Quartuccio L, Schiavon F, Zuliani F, et al. Long-term efficacy and improvement of health-related quality of life in patients with Takayasu's arteritis treated with infliximab. Clin Exp Rheumatol 2012:30:922-8.

108 Mekinian A, Néel A, Sibilia J, et al. Efficacy and tolerance of infliximab in refractory Takayasu arteritis: French multicentre study. Rheumatology 2012:51:882-6.

109 Serra R, Grande R, Buffone G, et al. Effects of glucocorticoids and tumor necrosis factor-alpha inhibitors on both clinical and molecular parameters in patients with Takayasu arteritis. J Pharmacol Pharmacother 2014;5:193-6.

110 Nunes G, Neves FS, Melo FM, et al. Takayasu arteritis: anti-TNF therapy in a Brazilian setting. Rev Bras Reumatol 2010;50:291-8

111 Ohigashi H, Tamura N, Ebana Y, et al. Effects of immunosuppressive and biological agents on refractory Takayasu arteritis patients unresponsive to glucocorticoid treatment. J Cardiol 2017;69:774-8

112 Hoffman GS, Leavitt RY, Kerr GS, et al. Treatment of glucocorticoid-resistant or relapsing Takayasu arteritis with methotrexate. Arthritis Rheum 1994;37:578-82.

113 de Souza AWS, de Almeida Agustinelli R, de Cinque Almeida $H$, et al. Leflunomide in Takayasu arteritis - A long term observational study. Rev Bras Reumatol Engl Ed 2016:56:371-5

114 Shinjo SK, Pereira RMR, Tizziani VAP, et al. Mycophenolate mofetil reduces disease activity and steroid dosage in Takayasu arteritis. Clin Rheumatol 2007:26:1871-5.

115 Li J, Yang Y, Zhao J, et al. The efficacy of mycophenolate mofetil for the treatment of Chinese Takayasu's arteritis. Sci Rep 2016;6.

116 Goel R, Danda D, Mathew J, et al. Mycophenolate mofetil in Takayasu's arteritis. Clin Rheumatol 2010:29:329-32.

117 Valsakumar AK, Valappil UC, Jorapur V, et al. Role of immunosuppressive therapy on clinical, immunological, and angiographic outcome in active Takayasu's arteritis. J Rheumatol 2003;30:1793-8.

118 Kermani TA, Schmidt J, Crowson CS, et al. Utility of erythrocyte sedimentation rate and C-reactive protein for the diagnosis of giant cell arteritis. Semin Arthritis Rheum 2012;41:866-71

119 Reichenbach S, Adler S, Bonel H, et al. Magnetic resonance Angiography in giant cell arteritis: results of a randomized controlled trial of tocilizumab in giant cell arteritis. Rheumatology 2018:57:982-6.

120 Gonzalez-Gay MA, Vazquez-Rodriguez TR, Gomez-Acebo I, et al. Strokes at time of disease diagnosis in a series of 287 patients with biopsy-proven giant cell arteritis. Medicine 2009;88:227-35.

121 Uddhammar A, Eriksson A-L, Nyström L, et al. Increased mortality due to cardiovascular disease in patients with giant cell arteritis in northern Sweden. J Rheumatol 2002;29:737-42

122 Nesher G, Berkun Y, Mates M, et al. Low-dose aspirin and prevention of cranial ischemic complications in giant cell arteritis. Arthritis Rheum 2004;50:1332-7.

123 Lee MS, Smith SD, Galor A, et al. Antiplatelet and anticoagulant therapy in patients with giant cell arteritis. Arthritis Rheum 2006;54:3306-9.

124 Narváez J, Bernad B, Gómez-Vaquero C, et al. Impact of antiplatelet therapy in the development of severe ischemic complications and in the outcome of patients with giant cell arteritis. Clin Exp Rheumatol 2008:26(3 Suppl 49):S57-62.

125 Berger CT, Wolbers M, Meyer $\mathrm{P}$, et al. High incidence of severe ischaemic complications in patients with giant cell arteritis irrespective of platelet count and size, and platelet inhibition. Rheumatology 2009;48:258-61.

126 Martínez-Taboada VM, López-Hoyos M, Narvaez J, et al. Effect of antiplatelet/ anticoagulant therapy on severe ischemic complications in patients with giant cell arteritis: a cumulative meta-analysis. Autoimmun Rev 2014;13:788-94.

127 McNeil JJ, Wolfe R, Woods RL, et al. Effect of aspirin on cardiovascular events and bleeding in the healthy elderly. N Eng/ J Med 2018;379:1509-18. 
128 Souza AWSde, Okamoto KYK, Abrantes F, et al. Giant cell arteritis: a multicenter observational study in Brazil. Clinics 2013;68:317-22.

129 Rosa Neto NS, Shinjo SK, Levy-Neto M, et al. Vascular surgery: the main risk factor for mortality in 146 Takayasu arteritis patients. Rheumatol Int 2017;37:1065-73.

130 Saadoun D, Lambert M, Mirault T, et al. Retrospective analysis of surgery versus endovascular intervention in Takayasu arteritis: a multicenter experience. Circulation 2012:125:813-9.

131 Labarca C, Makol A, Crowson CS, et al. Retrospective comparison of open versus endovascular procedures for Takayasu arteritis. J Rheumatol 2016;43:427-32.

132 Fields CE, Bower TC, Cooper LT, et al. Takayasu's arteritis: operative results and influence of disease activity. J Vasc Surg 2006;43:64-71.

133 Erbel R, Aboyans V, Boileau C, et al. 2014 ESC guidelines on the diagnosis and treatment of aortic diseases: document covering acute and chronic aortic diseases of the thoracic and abdominal aorta of the adult. the task Force for the diagnosis and treatment of aortic diseases of the European Society of cardiology (ESC). Eur Heart 2014;35:2873-926

134 Riambau V, Böckler D, Brunkwall J, et al. Editor's Choice - Management of Descending Thoracic Aorta Diseases: Clinical Practice Guidelines of the European Society for Vascular Surgery (ESVS). Eur J Vasc Endovasc Surg 2017;53:4-52.

135 Kermani TA, Warrington KJ, Crowson CS, et al. Large-vessel involvement in giant cell arteritis: a population-based cohort study of the incidence-trends and prognosis. Ann Rheum Dis 2013:72:1989-94.

136 Abularrage CJ, Slidell MB, Sidawy AN, et al. Quality of life of patients with Takayasu's arteritis. J Vasc Surg 2008;47:131-7. discussion 36-7.

137 Yilmaz N, Can M, Oner FA, et al. Impaired quality of life, disability and mental health in Takayasu's arteritis. Rheumatology 2013;52:1898-904.

138 Omma A, Erer B, Karadag O, et al. Remarkable damage along with poor quality of life in Takayasu arteritis: cross-sectional results of a long-term followed-up multicentre cohort. Clin Exp Rheumatol 2017;35 Suppl 103:77-82. 